\title{
Analysis on the strategy of Rural Revitalization in China in the perspective of intellectual property right
}

DOI: 10.46932/sfjdv3n1-090

Received in: Jan 30st, 2021

Accepted in: Feb 1th, 2022

\author{
Zhixiao Wu \\ Ph.D. \\ Shanxi University \\ Law School of Shanxi University (Dong Shan Campus), No. 63, Street of East Extension of Nan Zhong \\ Huan Road, Taiyuan City, Shanxi Province, China. \\ E-mail: wzxbd@163.com \\ Yifan Wen \\ Ph.D. \\ Shanxi University \\ Law School of Shanxi University (Dong Shan Campus), No. 63, Street of East Extension of Nan Zhong \\ Huan Road, Taiyuan City, Shanxi Province, China.
}

\begin{abstract}
It was proposed clearly in China's 14th Five-Year Plan to promote comprehensively rural revitalization. China will implement fully the strategy of rural revitalization, improve continuously the core competitiveness of agricultural products, speed up the implementation of rural construction, and take the road of socialist rural areas with Chinese characteristics. As an important part of the implementation of China's rural revitalization strategy, many of the relevant systems play a very obvious role in promoting the development of rural revitalization. Meanwhile, in the process of rural development in recent years, the demand for the protection of intellectual property rights related to agricultural development is also increasing. For this reason, it is essential to combine intellectual property rights with rural revitalization more effectively and accelerate the realization of high-quality rural development.
\end{abstract}

Keywords: Rural Revitalization, intellectual property right, Agricultural development, Agricultural trademark.

\section{STRATEGY OF RURAL REVITALIZATION IN CHINA}

The Strategy of Rural Revitalization was put forward by Xi Jinping in the 19th National Congress of the Communist Party of China in October 18, 2017. The report pointed out that the matter related to agriculture and farmers is a fundamental problem involved to the national economy and the people's livelihood. We must always take solving the " Agricultural-rural-farmer" problems as the top priority of the whole work and implement the Rural Revitalization Strategy. In 2018, the CPC Central Committee and the State Council issued the Strategic Plan for Rural Revitalization (2018-2011). On December 6, 2020, the Central Committee of the Communist Party of China and the State Council issued the Opinions 
of Realizing the Effective Connection between Consolidating and Expanding the Achievements of Poverty Eradication and Rural Revitalization, which put forward the key work. Namely, rural revitalization is an important task for the Party and the country at present. On February 21, 2021, the opinions were issued on comprehensive promotion of rural revitalization and accelerating agricultural and rural modernization by the CPC Central Committee and the State Council.

\section{DEVELOPMENT SCHEDULE OF RURAL REVITALIZATION STRATEGY}

In accordance with the strategic arrangement of the 19th National Congress of the Communist Party of China to win a decisive victory in building a well-off society in an all-round way and achieve the Second Centennial Goal by means of two stages, the central rural work conference defined the objectives and tasks of implementing the Rural Revitalization Strategy, as follows ${ }^{1}$.

By 2020, important progress will be made in rural revitalization, and the institutional framework and policy system will be basically formed. That is, China will obtain a solid comprehensive agricultural production capacity, form a high-quality agricultural supply system, and get integrated development among of primary, secondary and tertiary industries in rural.

By 2035, decisive progress will be made in Rural Revitalization, and modernization about agricultural and rural will be basically realized. Namely, the construction of rural infrastructure will be completed; the living environment will be improved; the ecological environment will be beautiful; and the basic public services in urban and rural areas will be equalized.

By 2050, rural areas will be revitalized in an all-round way, with strong agriculture, beautiful villages and rich farmers. In other words, the rural society will have been a high degree of civilization in perfectly good condition, civilized rural style and simple folk style. With the employment rate for farmers increasing, the channels for income are further expanded, as well as the living standards of rural residents continue to increase by then.

\section{SIGNIFICANCE OF RURAL REVITALIZATION STRATEGY}

The main contradiction in our society has been transformed into the one, between unbalanced and insufficient development of the society and people's growing needs for a better life. So, the primary problem we have to solve is the unbalanced development between urban and rural areas and the insufficient development of agriculture and rural areas.

Rural Revitalization Strategy is related to the realization of agricultural and rural modernization because without agricultural and rural modernization there will be no modernization of the whole country, which relate to the realization of the second Centennial goal of China. Therefore, the overall revitalization 
of the countryside is of overall and great historical significance for the comprehensive construction of socialist modern country.

\section{THE NECESSITY OF INTELLECTUAL PROPERTY RIGHTS TO THE STRATEGIC DEVELOPMENT OF RURAL REVITALIZATION}

\subsection{ACCELERATION OF CONNECTION BETWEEN POVERTY ALLEVIATION ACHIEVEMENTS} AND RURAL REVITALIZATION

In 2021, China wins an all-round victory in getting rid of poverty and being better off. In the battle of poverty alleviation around the country, a number of poor villages have become rich through industrial poverty alleviation. Industrial revitalization is the basis of Rural Revitalization. Relying on local natural resources in rural areas, with the help of a series of Poverty Alleviation Policies, many villages realize industrial development rapidly. Generally, rural industry is a compound one based on planting, breeding, agricultural product processing, agricultural product circulation and rural tourism ${ }^{2}$. It has achieved the goal of enabling farmers to achieve employment in their hometown and get rid of poverty as soon as possible, effectively solving the problem of absolute poverty in rural areas.

However, rural industry still faces many problems, such as backward industrial technology, low quality of labor force, difficulties in agricultural technology promotion and so on.

Intellectual property rights related to agriculture can provide a good medicine for the development of rural industry, promote the development of rural industry to higher quality, thus promoting the poverty alleviation achievements to benefit people more effectively, and then promoting high-quality development of rural areas.

\subsection{PROMOTING AGRICULTURAL DEVELOPMENT AND REALIZING RURAL MODERNIZATION}

In modern society, the development of agriculture is different from the "small-scale peasant economy" in the past. With the development of science and technology, agricultural modernization must be realized in China.

Agricultural modernization plays a leading role in rural revitalization, while the development of it depends on the progress of science and technology. Making good use of the intellectual property system can promote the development of agricultural science and technology, and encourage farmers to use it, for the realization of agricultural and rural modernization as soon as possible. 


\subsection{GREAT SIGNIFICANCE OF INTELLECTUAL PROPERTY RIGHTS TO CONSTRUCTION OF} RURAL SPIRITUAL CIVILIZATION

we should not only revitalize the economy, science and technology, but also promote cultural and ethical progress in rural vitalization.

Beautiful villages should not only have machines and equipment to improve efficiency and liberate farmers' hands, but also have cultural heritage that are consistent with the history and culture of the countryside. One should not lose the other in the construction of rural revitalization.

The copyright system in intellectual property rights plays an important role in protecting rural intangible cultural heritage, such as drama performances, dance works and music works, and so on.

villages can attract tourists by shooting propaganda videos and uploading them to short video platforms. Such rural works also need the protection of intellectual property rights.

otherwise, the films may be infringed, which will reduce the creative enthusiasm of the authors and affect the development of rural cultural industry and rural revitalization.

\section{ANALYSIS ON AGRICULTURAL INTELLECTUAL PROPERTY RIGHTS}

Agricultural intellectual property right belongs to the category of intellectual property. It not only has the characteristics of intangibility, exclusivity, regionality, timeliness and exclusion as intellectual property itself, but also has its own characteristics.

However, at present it has not formed a unified conclusion on agricultural intellectual property rights in academic circle. Generally speaking, agricultural intellectual property rights include agricultural patents, agricultural trademarks, new plant varieties, agricultural trade secrets, geographical indications of agricultural products and agricultural science and technology and so on.

On the one hand, agricultural intellectual property rights, as valuable wealth of rural areas and farmers, is closely related to Rural Revitalization and can accelerate it; on the other hand, it is difficult to define the value of agricultural intellectual property rights. At present, agricultural intellectual property rights mostly exist in the primary industry and fields related agricultural science and technology, ${ }^{3}$ and the formation of agricultural intellectual property rights is closely related to the natural environment, the growth habits of crops and other factors, so it is difficult to measure its achievements in a unified standard.

In addition, the most important feature of agricultural intellectual property right is that it depends on different natural environmental conditions. There are great differences in the environment between different provinces. Many factors, such as altitude, precipitation and temperature, will affect the development of agricultural intellectual property rights. Therefore, agricultural intellectual property rights are vulnerable to various risks ${ }^{4}$. 
Agricultural intellectual property rights also have certain social characteristics. Agriculture plays a fundamental role for national economic development in China, supporting 1.4 billion people and stabilizing society development.

Although the content related to agricultural intellectual property rights has made great progress in recent years, and the development momentum is good, there are still many problems.

For one thing, China has successively issued a series of legal documents on the protection of intellectual property rights, such as Trademark Law and Patent Law. However, there is still little involvement in agricultural intellectual property rights. The complete system of protection has not been formed.

For another, Agricultural modernization cannot be separated from the development of science and technology, and high-quality scientific and technological development needs relevant personnel to research, but China lacks talents in agricultural intellectual property rights.

We should optimize our own development environment, give policy encouragement and support to rural entrepreneurial talents, as well as constantly attracting high-quality talents to the countryside, and striving for more college graduates to build the countryside.

\section{CONCLUSION}

It was proposed clearly in China's 14th Five-Year Plan to promote comprehensively rural revitalization. The goal is to implement fully the strategy of rural revitalization, improve continuously the core competitiveness of agricultural products, speed up the implementation of rural construction, and take the road of socialist rural areas with Chinese characteristics. the primary problem we have to solve is the unbalanced development between urban and rural areas and the insufficient development of agriculture and rural areas. the overall revitalization of the countryside is of overall and great historical significance for the comprehensive construction of socialist modern country. It is necessity by means of intellectual property rights for the strategic development of rural revitalization. 


\section{REFERENCES}

1 Chinese government website : Opinions of the CPC Central Committee and the State Council on Implementing the Strategy of Rural Revitalization. Retrieved from: http://www.gov.cn

2 L. Haiyan, L. Zhuo, Research on the path of agricultural intellectual property helping Industrial Development under the strategic layout of Rural Revitalization, Agriculture and technology 40 (7) 2020) 161. DOI: 10.19754/j.nyyjs.20200415062

3 Z.Shu-lin, Agricultural Intellectual Property and Rural Industry Revitalization, Guizhou Ethnic Studies 41(1) (2020) DOI: 10.13965/j.cnki.gzmzyj10026959.2020.01.005

4 L. Haiyan, L. Zhuo, Research on the path of agricultural intellectual property helping Industrial Development under the strategic layout of Rural Revitalization, Agriculture and technology 40 (7) 2020） 162. DOI: 10.19754/j.nyyjs.20200415062 